\title{
VALIDATION AND VERIFICATION PLAN FOR SAFETY AND PRA CODES (U)
}

\author{
by M. J. Ades
}

Westinghouse Savannah River Company

Savannah River Site

Aiken, South Carolina 29808

Other Authors:

R. D. Crowe

(Westinghouse Hanford Company)

H. Toffer

(WHC)

This paper was prepared in connection with work done under Contract No. DE-AC09-89SR18035 with the U. S. Department of Energy. By acceptance of this paper, the publisher and/or recipient acknowledges the U.S. Government's right to retain a nonexclusive, royalty-free license in and to any copyright covering this paper, along with the righ : reproduce and to authorize others to reproduce all or part of the copyrighted paper. 


\section{DISC:I,AIMIR}

This report was prepared as an account of work sponsored by an agency ot the: linited States Government. Neither the United States Government nor any agency thereot, nor any of their employees, makes any warranty, express or implied, or assumes any legal liability or responsibility for the accuracy, completeness, or usefulness of any information, apparatus, product, or process disclosed, or represents that its use would not infringe privately owned rights. Reference herein to any specific commercial prociuct, process, or service by trade name, trademark, manufacturer, or otherwise does not necessarily constitute or imply its endorsement, recommendation, or favoring by the United States Government or any agency thereof. The views and opinions of authors expressed herein do not necessarily state or reflect those of the United States Government or any agency thereot.

Ihis report has been reproduced directy from the best avalable copy.

Available to DOE and DOE contractors from the Office of Scientitic and lechnical Information, P.O. Box 62, Oak Ridge, TN 37831 ; prices available from (615) 576-8.4()1, FIS $626-8401$

Available to the public from the National Technical Information Service, U.S. Deparment of Commerce, 5285 Port Royal Rd., Springfield, VA 22161. 
Verification and Validation Plan Revision Log

\begin{tabular}{|c|c|c|c|}
\hline $\begin{array}{l}\text { Revision } \\
\text { Number }\end{array}$ & $\begin{array}{l}\text { Affected } \\
\text { (pages) }\end{array}$ & $\begin{array}{l}\text { Effective } \\
\text { Date }\end{array}$ & Description of Revision \\
\hline () & All & $5 / 90$ & Original Issue \\
\hline \multirow[t]{3}{*}{1} & All & $3 / 91$ & $\begin{array}{l}\text { Revision to incorporate } \\
\text { reviewers suggestions and } \\
\text { comments. }\end{array}$ \\
\hline & & & WSRC-RP--90-433-Rev.1 \\
\hline & & & DE93 005699 \\
\hline
\end{tabular}


PROJECT: Code Certification

DOCLMENT: WSRC-RP-90.433, KEV-I

TITLE: Validation and Verification Plan for Safety and PRA Codes (U)

TASK:

\section{APPROVALS}

M. J. Hitchler, Manager

Reactor Safety Research

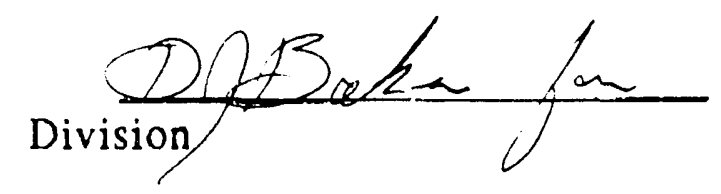

Date: $3 / 27 / 9$

L. A. Wooten, Manager

Safety Analysis Group

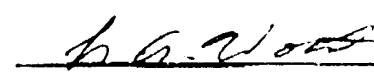

Date: $4 / 1691$

D. A. Sharp, Manager
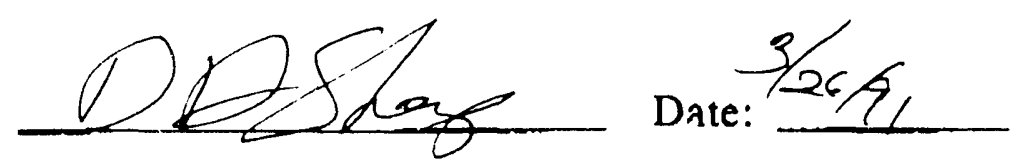

Risk Assessment Group

D. J. Baker, Manager Reactor Safety Control Group

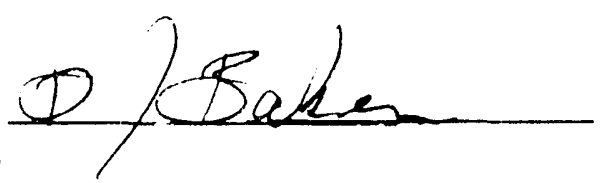

Date: $3 / 27 / 91$

J. Pardo

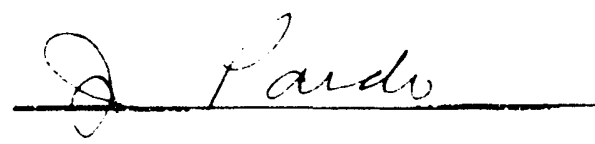

Date: $3 / 26 ! 9$

SRL Quality Section

K. R. O'Kula, Manager

$K R \quad M \cdot M h$

Date: $3 / 22 / 9$,

Source Term Evaluation Group 


\section{CONTENTS}

1.0 SUMMARY

2.0 INTRODUCTION 2

3.0 OBJECTIVES OF PLAN 3

4.0 BASIC ASSUMPTIONS 4

5.0 LIST AND DESCRIPTION OF CODES COVERED 4

6.0 QA REQUIREMENTS 5

7.0 ACTION MATRIX

8.0 RESOURCE REQUIREMENTS 15

9.0 TIMF SCHEDULE 15

10.0 CONCLUSIONS 15

11.0 REFERENCES 16

$\begin{array}{ll}\text { TABLES } & 17\end{array}$

$\begin{array}{ll}\text { FIGURES } & 18\end{array}$

APPENDIX A - GLOSSARY OF TERMS 20

APPENDIX B - INDIVIDUAL CODE DESCRIPTIONS 23 


\subsection{SUMMARY}

A verification and validation ( $V \& V$ ) plan for computer codes used for safety analysis and probabilistic risk assessment calculations has been prepared. The plan follows closely the "Verification and Validation Plan for Reactor Analysis Computer Codes" WSRC-RD-89-1249 (Reference 1). The present plan fulfills the commitments by Westinghouse Savannah River Company (WSRC) to the Department of Energy Savannah River Office (DOE-SRO) to bring the essential safety analysis and probabilistic risk assessment codes in compliance with verification and validation requirements as discussed in the "DOE Safety Evaluation Report", Section 5.8 "Verification of Computer Codes" (Reference 2).

The V\&V plan is in compliance with the WSRC software quality assurance requirements as contained in Reference 3 and specifically QAP 20-1, "Software Quality Assurance" and the appropriate SA\&RM procedures derived from QAP 20-1 (Reference 4).

The plan stresses verification and validation by demonstrating successful application of the code to predict benchmarks. conceptual solutions, intercode comparisons, and measurements. Such an approach is consistent with industry accepted practices and WSRC software quality assurance documentation.

An action matrix and a time schedule have been included in the plan. These items identify what is required to achieve verification and validation of the codes, and a proposed time table that this will be accomplished on.

A list of computer codes covered by the verification and validation plan has been established. A description of each of the codes is provided in the appendix. The action matrix identifies specific requirements that need to be met to achieve the verification and validation plan's objectives.

Large segments of information called for in the action plan have been generated in the past, especially for codes developed by off-site contractors. However, proper documentation needs to be identified, assembled, and updated. Some validation and benchmark calculations will have to be performed for the latest version of the computer codes and for specific Westinghouse Savannah River Company (WSRC) reactor applications.

Validation techniques used for safety codes could differ significantly from those applied to probabilistic risk assessment codes. These differences are pointed out throughout the document. 


\subsection{INTRODUCTION}

As a consequence of the Department of Energy (DOE) review of Savannah River Site reactor operations, the DOE requested WSRC to provide quality assurance for safety related software for technical programs essential to the safety of reactor operation (Reference 2). Safety related software consists of those computer codes used in safety analyses performed in support of the Technical Specifications, Safety Analysis Report and Probabilistic Risk Assessment. To respond to the DOE request, a verification and validation plan has been developed. The plan covers computer codes used for safety analysis, severe accident evaluations, safety dose assessment, and probabilistic risk assessment.

A majority of the codes encompassed by this plan were developed offsite under different quality assurance requirements. This plan puts in place the process and schedule to implement consistent requirements for all the codes and to establish documented verification and validation for the codes. Emphasis in this effort will be in demonstrating the successful application of the codes and their ability to predict reactor conditions, replicate test data, and match benchmarks and thereby bringing the codes into compliance with current quality assurance requirements.

This plan folds the Safety Analysis and Probabilistic Risk Assessment (SA\&PRA) codes into a plan similar to the plan developed for Reactor Analysis codes, Reference 1. In addition, the Reactor Restart Quality Assessment Report, (Reference 5) and QAP 20-1, Quality Assurance Manual (Reference 3) were used in the preparation of the $V \& V$ plan.

This plan applies to Safety Analysis and Risk Management (SA\&RM) "high impact" software used directly in the design, construction, operation, modification, repair, or maintenance of facilities and components whose design classification is "Nuclear Safety" or "Critical Protection" as defined by QAP 3-1 of Reference 3.

While only "high impact" software is directly covered by this plan, good engineering practice suggests that applying similar practices on "low impact" software would be prudent. This would facilitate upgrading the impact level of a code should this become necessary.

The successful implementation of the plan requires an understanding of what is meant by code verification and code validation and the relationship of these terms to the WSRC quality assurance documentation. 
Verification denotes the process which establishes that the theory is correct and has been properly coded and that the various code mociules are functionally coupled to process information as required.

Validation is the process of establishing how well a computer code meets specified requirements such as reproducing experimental data obtained from special facilities or from controlled experiments in operating facilities, from normal operation or from benchmarking activities. Benchmarking refers to the process of evaluating the performance of one computer code relative to another code or relative to an exact solution.

Additional definitions of words can be found in the glossary of terms found in Appendix A.

\subsection{OBJECTIVES OF PLAN}

The objective of the Verification and Validation Plan for SA\&RM codes is to establish a verification and validation plan as identified in the DOE Safety Evaluation Report (Reference 2).

The specific points addressed in the plan include:

o Identification of "high impact" computer codes requiring verification and validation as defined by QAP 3-1 of Reference 3,

o Ensuring that user documentation is adequate, complete and available,

o Documentation of an experimental or theoretical bases, as applicable, for the code calculations and linking the results to tests conducted, and

o Development of standard test problems, establishment of an approach for validation and verification of identified SA\&RM software to ensure proper definition of the requirements for installation and to identify limitations for code usage. 


\subsection{BASIC ASSUMPTIONS}

All computer codes addressed by this plan will be dealt with in a manner similar to the way the Reactor Physics and Thermal Hydraulics codes are presently being processed. DOE approval has already been obtained for Reactor Physics Verification and Validation Plan. However, for the Probabilistic Risk Assessment (PRA) codes, a modified strategy may become necessary to incorporate the different logic inherent in this type of codes. This problem will be addressed when it arises in the process of validating the codes.

For the safety analysis and probabilistic risk assessment activities, a large number of codes were procured from offsite vendors, other codes were developed on site, and others are still being developed in conformance to present quality assurance (QA) requirements. It is believed that codes that have been used on site for a number of years and some other well accepted analysis tools developed off site have been successful in predicting safety pararneters and trends. To a large extent, the required information for V\&V may be in existence. Some editing may be required to bring such information into desired formats. Validation and verification and code test problems have to be appropriate for WSRC applications.

The V\&V plan is a living document. It is anticipated that the document will be updated as additional SA\&RM software is identified as high impact codes or will be modified if a code identified in this plan is downgraded in impact level.

This plan identifies the tasks to be performed to verify and validate the SA\&RM high impact software codes. The procedure (Reference 4) to be used is described in the 1Q35, SA\&RM QA Implementing Procedures. Together, these two documents provide the method for satisfying the applicable QA requirements for critical software as defined by $1 \mathrm{Q}$, the WSRC Quality Assurance Manual (Reference 3).

\subsection{LIST AND DESCRIPTION ()F CODES COVERED}

A list of pertinent safety analysis, severe decident analysis, dose assessment, and probabilistic risk assessment coder ha heen assembled. Code descriptions for the listed codes are in Appendix $A$. The covered codes are: 


$\begin{array}{cccc}\begin{array}{c}\text { Safety } \\ \text { Analysis }\end{array} & \begin{array}{c}\text { Severe } \\ \text { Accident }\end{array} & \begin{array}{c}\text { Dose } \\ \text { Assessment }\end{array} & \begin{array}{c}\text { Probabilistic } \\ \text { Assessment }\end{array} \\ \text { AA3* }_{\text {MARY* }}^{*} & \text { MELCOR } & \text { AXAIR* } & \text { EVNTRE } \\ \text { PIPEFLOW } & & \text { NRC145/2* } & \text { LHS } \\ & & & \text { MACCS } \\ & & \text { PREP } \\ & & \text { SETS } \\ & & \text { TEMAC }\end{array}$

${ }^{*}$ High impact software as defined by QAP $20-1$

\subsection{QA REQUIREMENTS}

The Verification and Validation Plan is designed to satisfy the requirements for software quality assurance as described in the SA\&RM Quality Assurance Prosedures, 1Q35, in varticular, procedure 1.13. These procedures implement the requirements of the WSRC Quality Assurance Manual, 1Q.

\subsection{ACTION MATRIX}

An action matrix for the $\mathrm{V} \& \mathrm{~V}$ plan has been developed and is shown in Figures 1 and 2. The matrix identifies the different type of information that needs to be assembled for each code to establish a documented code verification and validation. The matrix lists and defines the activities that will be required for $\mathrm{V} \& \mathrm{~V}$ and also serves as a useful tracking mechanism for monitoring the completion of these activities.

In the matrix, the names of the various codes are listed, as well as a series of action items. These activities are grouped by theme. The BASIC group deals with common requirements for each of the codes. The topics in the THEORY group pertain to confirmation of code verification. The items listed under EXPERIMF $;$ TS and BENCHMARKS deal with the validation effort. The CONCLUSIONS category establishes the completion of the tasks identified in the verification and validation action matrix (V\&VAM).

Additional information on the V\&VAM is contained in this section as detailed descriptions of what is needed to satisfy each topic. Not all the boxes are relevant for each computer code. For example, the PRA codes will not have experimentally validated results. Consequently, a section of the PRA Action Matrix has been deleted. 
For all codes, there are two ways for a box to be completed and checked off; either by performing the tasks identified for each box or by establishing that this specific task is not relevant for the particular code. In either case, this information is to be included in the documentation for the particular action matrix box.

The following sections give a detailed description of what is called for under the specific action items. The criteria by which these action items are measured is specified within the software development plan (SDP) described below and by compliance with procedures (Reference 4).

\subsection{BASIC REQUIREMENTS}

\subsubsection{Software Development Plan (SDP)}

Is a SDP in place for the particular code?

A software development plan (Reference 4) should be in place for all codes being validated. This plan should state the problem, describe the proposed solution method, identify the software, and include any required design reviews (Reference 1). The SDP shall also contain a software requirements specification (SRSP). The SRSP documents the fu-ctions that the software must perform and the environment in which it must periorm. The SRSP also defines the success criteria for measuring code performance.

\subsubsection{User Manuals in Place}

Is adequate documentation in place for a person to use the code?

Adequate user documentation should exist so that a person with technical familiarity and a background in the appropriate field would be able to gain sufficient knowledge of the computer code's input parameters to execute relevant calculations on a controlled version. A knowledge of the specific computer's operating system is assumed.

\subsubsection{Configuration Control Plan}

Has a configuration control plan been established for the particular code?

A code that is being validated should be under a configuration control plan. The version of the code should be frozen, users and theory manuals should be in piace, and approved procedures and methods to perform the validations sinould be established. 


\subsubsection{Code Portability}

Is the computer code portable from one computer/operating system to another computer/operating system?

The computer environment is changed periodically. New operating systerns are implemented and more advanced computers are installed. The computer code should be written in a language and in a manner that lends itself to portability. Portability of a code may be dictated by its application. The requirements of portability for the individual codes must be addressed including identifying if there is a need to run the code on other computers and assessing conversion difficulties.

\subsection{VERIFICATION OF THEORY}

\subsubsection{Appropriate Theory}

Does an established, accepted theoretical basis exist for the code?

Computer codes that model a physical process, entity or condition, or a set of logical sequences require a theoretical or empirical description of the phenomenon or process or of the logic sequences being investigated. This description or model must be an appropriate representation of the actual physical situation for the computer code. The theory must be rele'vant to the problem being solved such that all pertinent phenomena and parameters are considered and the treatment of independent variables is correct. An exact mathematical description may be beyond existing computational capabilities and therefore approximations to the theory may have to be introduced. The effect of these approximations and the conditions for which they are valid should be evaluated before the computer code theory can be accepted as appropriate.

\subsubsection{Theory Documented}

Has the theory for the code been documented?

The basis for the theoretical treatment should come from established engineering theory and practices whenever possible. Documentation to substantiate the theory such as textbooks, reports, journals and internally reviewed reports should be identified and their availability established. 


\subsubsection{Coding Consistency}

Has the theory been coded properly and is the software functioning as required?

The solutions or mathematical descriptions have to be transiated into a computer code language. There must be consistency between the coding and the calculational logic. Coded modules have to interact furctionally to meet code operation objectives. For cemputer codes developed several years ago, this process, although periormed, may not have been documented. As an alternative, the check of the coding consistency for these codes may be in the demonstrated ability of the code to predict reproducible and verifiable results.

\subsubsection{Theory Verified Conceptually}

Was the theory developed from first principles?

Tt. tevelopment of a theoretical description for a particular problem may involve combining several specific concepts. The interaction berween the theoretical models and underlying approximations has to be identified and tested to insure that the concepts and applications of the individual theoretical models combine to create a valid unified theoretical description.

\subsubsection{Theory Verified by Experiment}

Was the theory verified with experimental data? (not applicable to PRA codes)

Most theoretical descriptions of a problem can be tested and verified by experimental measurements. A theory that has demonstrated its validity by predicting or interpreting experimental results for one set of conditions can be applied to a new set of problems, provided the differences in conditions are understood.

PRA codes and some Accident Analysis codes cannot be tested nor verified by comparison with specific experimental measurement. Rather, they are validated on how well they predict intuitive trends, distributions, and logical sequences. 


\subsubsection{Theory Documentation Adequate}

Does a document exist that adequately explains the theory for the code?

Documentation is required to demonstrate the appropriateness of the theoretical development. Is there conclusive documentation to support the assertions made in answer to the previous questions? This documentation should be in the open literature or be in internal documents that have been through an appropriate technical review.

\subsection{VALIDA'IION USING EXPERIMENTAL DATA}

(This entire section is not applicable to the PRA codes and has been deleted from the PRA codes action matrix.)

\subsubsection{Tests in Experimental Facilities}

Have tests been performed in special facilities that are applicable to code validation?

The accuracy of a computer code in replicating a physical situation can be established by comparing results to data obtained from experiments in special test facilities. The first step in this process would be to identify relevant test data. The value of an individual test will depend on how closely it corresponds to the computer code's intended purpose, the range of variables measured during the test, and the quality and accuracy of the data collected.

\subsubsection{Tests in Operating Facilities}

Have controlled tests been performed in operating facilities that can be used for code validation?

Another way of measuring the accuracy of $d$ code is by comparison to measurements made during special experiments in operating facilities. While experimental facilities may allow measurement of conditions that exceed allowable conditions for an operating tucluty. the experimental facilities may not replicate prototypic conditions. Therefore. special tests in operating facilities are important to establish values of parameters in operating environments. Again, the worth of these data depend on the accuracy, quality and completeness of the data. 


\subsubsection{Data from Operating Facilities}

Are data available from operating facilities for code validation?

During normal operation, a large quantity of data is regularly collected. These data are potentially a very useful source of information for validating the functions of a computer code. The data relevant for comparison with the computer code predictions need to be identified. This information may exist in stored data records of operating conditions or may have to be flagged for collection during normal operation after restart. The quality of older data has to be evaluated whereas the quality of data collected in the future can be controlled.

\subsubsection{Test Data Documented}

Are the data from any of the test and operating facilities documented?

The critical consideration in determining the value of existing test data for code validation is the quantity and quality of the documentation describing the conditions of the tests and controls used in collecting the data. The documentation requirements apply to all sources of data used for validation.

\subsubsection{Appropriate Data Quality}

Is the quality and applicability of the data such that it can be used for validation?

The experimental or test data used for code validation should be collected under experimental or operating conditions subject to the applicable QA procedures ( i.e., QAP 2-3, Control of Research and Development Activities, Reference 3 ). The conditions dictated by present $Q A$ requirements insure that the test data are of appropriate quality. For data from programs with less stringent QA requirements, such as would be the case for older test data or data from scoping studies, several methods are listed in QAP 2-3 for qualifying the data including use of corroborating data, confirmatory testing, analysis of controls used, and independent technical review.

\subsubsection{Validation Performed}

i the validations been performed with data sources?

Once the quality of the validation data has been established, code testing shall be conducted in accordance with the SA\&RM Procedure 1.13, Section 5.4, Test 
and Installation Section. The results of the validation computations shall be compared with the test data to provide a performance evaluation of the computer code for the specific application and demonstrate that the criteria described in the specification requirements are satisfied. This should include evaluating the ability of the software to model the processes or the phenomena over a specific range of variables. The comparison should attempt to demonstrate code applicability over a large range of input variables. Validation has to be performed with either configuration controlled software or in accordance with a specified configuration conirol plan. The results of the validation for critical applications must be documented and undergo technical review as described in QA procedures. Past validations must be reviewed for acceptability based on the details included in the documentation.

\subsubsection{Validation Documentation Adequate}

Has the validation been documented in an adequate manner?

Adequate documentation for validation requires complete records of the test data used for the validation, identification of any supporting software used including data files, codes, library routines, and systems software. Specification of the valid range and inputs and outputs of the computer runs need to be recorded. Past validation documents have to be judged on how well they meet the intent of present QA requirements (Reference 4).

\subsection{VALIDATION USING BENCHMARKS}

\subsubsection{Benchmark Requirements Identified}

Have the benchmark and specific requirements for the code in question been established?

The benchmark tests need to exercise the full range of the code's capabilities to demonstrate the computer code performs as intended. The tests should be as representative as possible of the actual conditions for which the computer code is intended. The range of inputs and anticipated outputs needs to be identified. The methods used to compare the benchmark data and calculated resuits should be specified.

Identification of benchmark requirements is important to PRA code validation since benchmark testing is one of the primary means of PRA code validation. 


\subsubsection{Similar Code Comparison}

Are similar certified codes available that could duplicate the desired calculations and thereby provide a benchmark?

This type of code benchmarking requires identifying another computer code that performs similar calculations. Both computer codes attempt to solve the same prublem and the resulting calculations are compared.

\section{7.‥3 Exact Solution Comparison}

Are exact solutions available against which the computer code can be tested?

In many cases, the model description used in some computer codes can be simplified to allow for an analytical or exact solution. This can give an absolute measure of the code performance. Such solutions can provide part of the benclimarking even if only a limited range of the inputs is exercised. Exact solution comparisons may not be appropriate for PRA codes. For these codes, comparisons of trends and shapes of distribution are more important.

\subsubsection{Industry Benchmark Comparison}

Are there industry accepted benchmark problems available against which the computer code can be tested?

Several benchmark problems have been identified by industry and are used to test new codes. Some of these benchmarks may be appropriate for testing of the codes on the list. In such a case, they would provide a significant test for the computer codes being validated.

\subsubsection{Comparisons Documented}

Have the comparisons to other codes, to exact solutions and/or industry accepted benchmarks been documented?

The goal of the benchmark tests is to evaluate the ability of the software to model the processes or phenomena over a specific range of variables. The results of the analysis must be documented to include identification of the sources of comparison data, the range of specific inputs, methods of evaluating the test results, anu description of how the testing was conducted. 


\subsubsection{Benchmark Documentation Adequate}

Is the documentation of the benchmark calculations adequate to pass a technical review?

Adequate documentation for benchmarking requires complete records of the comparison test data used for the tests, identification of any supporting software including data files, codes, library routines, and systems software and specification of the range of inputs and outputs of the code tested. Past benchmarking test documents have to be judged on how well they met the intent of present QA requirements (Reference 4).

\subsection{CONCLUDING TASKS}

\subsubsection{Requirements Verification Review}

Has a code requirements verification review been completed?

Every code should be passed through a technical review to establish if the verification steps completed in the theory section are sufficiently complete to declare that the code is considered verified. An independent technical review (Reference 4) would have to be performed by WSRC personnel with support from consultants as appropriate. The criteria by which this review will be conducted are contained in Section 7.1.1. A report generated by this group would recommend to management the disposition of the verification for a particular code.

\subsubsection{Verification Completed}

Has the computer code verification process been completed?

Following the technical review group recommendation, verification of a particular code is accepted by the management of the specific organization. The verified code under its configuration control plan will be assigned to the control of a specific code proprietor. It will be the proprietors' responsibility to ensure that code verification is maintained through subsequent configuration and computer system changes. A letter or report by the appropriate manager will be issued upon the completion of this activity.

\subsubsection{Standard Set of Test Problems}

Has a standard set of test problems been established for validation, benchmarking, and code testing purposes? 
As an outcome of the validation effort, a standard set of documented test problems should evolve that can be processed subsequent to any code modification to ensure consistency. The standard set of test problems can include comparisons to experimental data, other codes, exact solutions, and industry accepted benchmarks. The set should span the potential range of applications for the code and should test features and special data records of interest. Development of the testing criteria and testing procedures is covered in Reference 4. These standard test problems are also used for periodic testing of the software (see Reference 4).

\subsubsection{Validation/Benchmarking Review}

Has a code validation/benchmarking review been completed?

Every code should be passed through a technical review to establish if the validation/benchmarking steps are sufficiently complete to declare that the code is considered validated and benchmarked. An independent technical review group would have to be established composed of WSRC personnel with support from consultants as appropriate and function under the accepted QA requirements (Reference 4). The criteria by which this review will be conducted are contained in Section 7.1.1. The reviewers should be independent of the proprietors or originators of the software. A report generated by this group would recommend to management the disposition of the validation/benchmarking for a particular code.

\subsubsection{Validation/Benchmarking Completed}

Has the computer code validation/benchmarking process been completed?

Following the technical review group recommendation, validation and benchmarking of a particular code is accepted by the management of the specific organization. The validated and henchmarked code under its configuration control plan will be assigned (1) the control of a specific code proprietor. It will be the proprietor's repromithlity to ensure that code validation and benchmarking are manntuncid inrough subsequent configuration and computer system changes. A report $h$ the appropriate WSRC manager will satisfy the Department of Energy Savannah River Office of the completion of this activity. 


\subsection{RESOURCE REQUIREMENTS}

The resource requirements will be established as the second phase of the verification and validation effort. After publication of the plan, an assessment will be made for each code to determine the extent of verification and validation materials that are in existence, and the amount of information and documentation that needs to be generated. Based on the assessment report, resource allocations and more realistic time schedules for each code will be established to achieve compliance with verification and validation requirements.

\subsection{TIME SCHEDULE}

The proposed time schedule for completion of the verification and validation efforts for all codes is given in Figure 3, Schedule for Validation and Verification Proposed Plan Activities. Milestones 1, 2, and 3 are preliminary to the effort leading to the completion of milestones 4 through 7 . Milestone 3 established what pertinent information is in existence and what needs to be done for each specific code to bring it into compliance with the verification and validation plan requirements.

\subsection{CONCLUSIONS}

The Verification and Validation Plan has been established. Implementation of this Plan will bring computer codes essential to safety analysis and PRA evaluations into compliance with SA\&RM software quality assurance requirements. 


\subsection{REFERENCES}

1. WSRC-RD-89-1249, "Verification and Validation Plan for Reactor Analysis Computer Codes (U)," H. Toffer, R. D. Crowe, K. N. Schwinkendorf (WHC), and R. E. Pevey (WSRC), 1989.

2. DOE Safety Evaluation Report, Section 5.8, Verification of Computer Codes, Rev. 0, March 15, 1990.

3. 1Q, "Quality Assurance Manual," April 1, 1990.

4. 1Q-35, "SA\&RM Quality Assurance Procedures."

5. "Reactor Restart Soltware Quality Assurance Assessment Final Report," S. B. Ailes, A. C. Spencer, and D. A. Bevard, May 3, 1990. 
Table 1. Proposed Schedule for Validation and Verification Plan Activities SA\&RM Codes

High Impact $\underline{\text { Other Codes }}$

Milestones

1. Complete a Verification and

$5 / 31 / 90$

Validation Plan (draft)

2. Complete Computer Code Configuration

$5 / 31 / 90$

$5 / 31 / 90$

Control Plan (draft)

3. Source Material and Activity

$9 / 28 / 90$

$9 / 28 / 90$

Assessment for each code completed (draft)

4. Basics and Theory Section of

$5 / 31 / 91$

$9 / 30 / 91$

Verification Completed

5. Standard Set of Test Problems

$6 / 30 / 91$

$1 / 31 / 92$

in place and Documented

Validation Review Complete

6. Verification Review Completed

$7 / 31 / 91$

$3 / 31 / 92$

Experimental and Benchmark Section of Validation Completed

7. Review Comments resolved

$9 / 30 / 91$

$9 / 30 / 92$

Validation and Verification

Activities Finished 
Figure 1

\section{Verification and Validation Plan Action Matrix Safety Analysis Codes}

Software Development Plan User Manuals in Place Configuration Control Plan Code Portability

Appropriate Theory

Theory Documented Coding Consistency

Theory Verified Conceptually Theory Verified by Experiments

Theory Documentation Adequate

Tests in Experimental Facilities Tests in Operating Facilities Data from Operating Facilities Test Data Documented Appropriate Data Quality Validation Performed Validation Documentation Adequate

Benchmark Requirements Identified Similar Code Comparison Exact Solution Comparison Industry Benchmark Comparison Comparisons Documented Benchmark Documentation Adequate

RequirementsVerification Review Verification Completed

Standard Set of Test Problems Validation/Benchmarking Review Validation/Benchmarking Completed

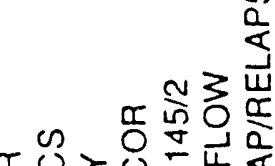

$\frac{a}{\frac{a}{a}}$

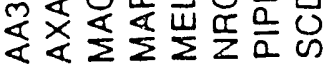

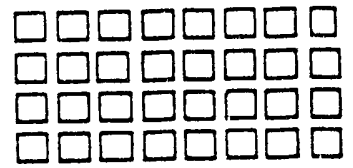

3
0
$\infty$
$\infty$
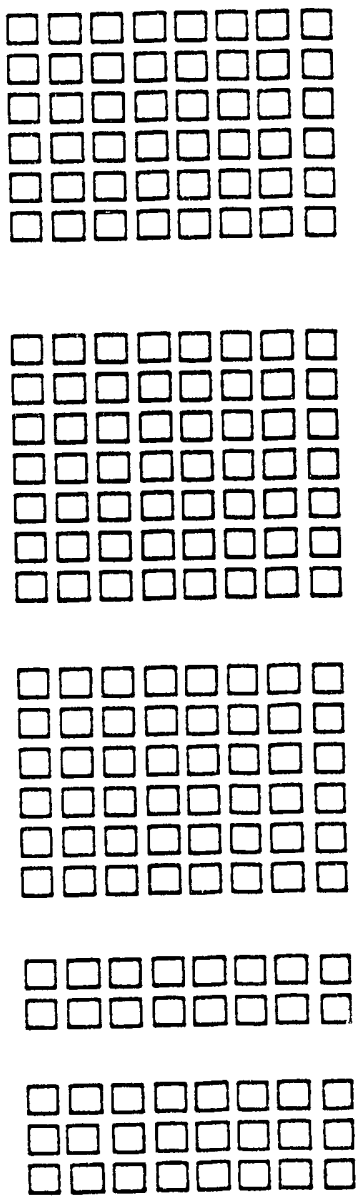


\section{APPENDIX A}

\section{Glossary of Terms}

The following definitions are provided to assure a common understanding of terms as they are used in this plan and other WSRC documents.

benchmarking. The process of validation performed by evaluating the performance of one computer code relative to another code or relative to an exact solution.

certification. As applied to existing software, is the process of determining, verifying, and attesting in writing to the qualification of software used in critical applications. Assurance is provided that the software has been properly reviewed and documented for verification, validation, user qualifications, and configuration control.

code control custodian. The person or persons in Computer Technology responsible for performing the required code configuration management for the identified codes.

code proprietor. A user identified for each code and usually in the owner organization, responsible for making code alterations, advising other users and interfacing with code control custodian.

configuration control. A system to manage and control computer software to provide a certified version of a code for the qualified user. Configuration control prevents unauthorized changes or use of the software coding and establishes a method of handling discrepancies including correction of errors. It also governs retention of supporting documentation such as certification records, user documentation, installation instructions, and benchmark testing results.

designer. The person, or persons who produce the product for the owner. The owner and designer may both be members of SA\&RM or the designer may be another organization either within or outside WSRC.

existing software. All software used within SA\&RM that was in use or in development prior to the effective date of the initial issue of the SA\&RM QA Procedure 1.13 is considered as existing software. 
life cycle phase. The period of time during the software development or operation that can be characterized by a primary type of activity (such as design and testing) that is being conducted. The software life cycles include a requirements phase, a design and implementation phase, an installation phase and checkout phase, an operation and maintenance phase and a retirement phase. These phases may overlap one another. For V\&V purposes, no phase is concluded until its development products are fully verified.

owner/owner organization. The person, or persons either within SA\&RM or outside, responsible for the defining or identifying the particular software product, for describing the needs, functional requirements, and constraints and for providing verifiable criteria for accepting or rejecting the software product.

portability. Describes ability of a code to be processed on more than one computer/operating system.

software requirements specification. Documentation of the essential requirements (functions, performance, design constraints, and attributes) of the software and its interfaces.

system software. Software designed for a specific computer or a family of computer systems to facilitate the operation and maintenance of the computer system and associated programs, for example operating systems, compilers, and utilities.

testing. An element of the validation process to evaluate the ability of the software to meet the criteria established prior to the beggining of the software development phase. Testing also ensures continued reliable operation of the software after it is placed in use.

test plan. A document describing the approach to be taken for intended testing activities. The plan typically identifies the items to be tested, the testing to be performed, test sequences, personnel requirements, and evaluation criteria.

test procedure. A document specifying a sequence of actions for executing a test.

users. The person, or persons, who actually operate or interact directly with the software program. Three levels of users have been identified based on user experience, education and ability in the SA\&RM certification plan. 
user qualification. Identifies the minimum levels of proficiency and authorization required for individuals to use certified software for critical application computations.

verification. The process which estaolishes that the theory is correct and has been properly coded and that the various code modules are functionally coupled to process information as required.

validation. The process of establishing how well a computer code meets specified requirements such as reproducing experimental data obtained from special facilities or from controlled experiments in operating facilities, from normal operation or from benchmarking activities. 


\section{APPENDIX B}

Individual Code Descriptions for:

AA3
AXAIR-89 AND NRC-145-2
EVNTRE
LHS
MACCS
MARY
MELCOR/SR
PIPEFLOW
PREP
SCDAP/RELAP5
SETS
TEMAC


Code Title: AA3

Code Description

The AA3 computer code models the coupled neutronic, thermal hydraulic, and engineering aspects of the WSRC reactors, including the assemblies comprising the reactor core, the primary and secondary coolant loops, and the protective instrument system. The neutronic calculations use standard point kinetics equations to obtain the relative power transient, with provision to use the quasi-static adiabatic approximation, if desired. For the latter case, the preincident and postincident static power distributions are represented as histograms of peaking factors expressed relative to explicitly computed zoneaverage assemblies. A complete description of the code is provided in two manuals, DPSTM-120 and DPSTM-120-1.

\section{Database Description}

The database to be provided by JOSHUA input recorded is fully described in DPSTM-120 and DPSTM-120-1.

\section{Code Applications}

The code has been used to establish confinement protection limits (limit on steam formation) as well as general transient analysis. Proper use of suitable input allows the code to be used for a wide variety of neutronic and thermal response analyses. At the present time, the correlations for the onset and subsequent behavior of steam during a transient are not certified. Hence, the code should be not used for critical calculations in which significant steam is expected to be formed.

\section{Historical Development}

AA3 is the latest generation of a coupled neutronic, thermal hydraulic, accident analysis code initially developed in the carly l'af()'s as the BURP code. Successive versions of the code (COMBINF. 1.11. BIRD, AAMZON, AA3 [now called AA3-Version 1], BB3) added neu kestures (steam generation and subsequent flow recovery, secondary cowling hop and automatic shutdown systems, increased number of assembly ivpes. moderator-to-coolant heat transfer and ABS/SC simulation, steam formation and condensation in the moderator space with resulting pressure under the top shiel.1, and explicit calculation of histogram assemblies for losi-of-flow transients, respectively). Oiher, special purpose, version existed (AA. CC3) for test purposes only and were never in general use. 
Code Title: AXAIR-89 and NRC-145-2

Code Description

Both codes were written at SRL to calculate dose to personnel using a method consistent with NRC Regulatory Guide 1.145. The codes have been used extensively to calculate dose to individuals that could result from accidental releases of radioactivity by SRS reactors.

Database Description

The codes use measured meteorology (wind speed, direction, and stability) from locations on the SRS to calculate the probability of dose. Input parameters describe the released isotopes, release time, and physical characteristics of the release and terrain.

Code Applications

Calculate dose to individuals on and off the SRS resulting from a radioactivity release in a reactor accident.

\section{Historical Development}

NRC-145-2 was written in 1982. AXAIR has several versions and is widely used at SRL. It was a modification of NRC-145-2 written initially in 1985. The version to be used for dose calculations from reactor accidents is AXAIR-89, which was written in 1989. 


\section{Code Title: EVNTRE}

\section{Code Description}

The EVNTRE code was developed at Sandia National Laboratories. EVNTRE is designed to process the large accident progression event trees and associated files used in probabilistic risk analyses for nuclear power plants. However, the general nature of EVNTRE makes it applicable to a wide variety of analyses that involve the investigation of a progression of events which lead to a large number of sets of conditions or scenarios. The EVNTRE code efficiently processes large, complex event trees. It has the capability to assign probabilities to event tree branch points in several different ways, to classify pathways or outcomes into user-specified groupings, and to sample input distributions of probabilities and parameters.

\section{Database Description}

There are two major input data files for EVNTRE.

1. Tree Definition File: Supplies the event tree structure and default probability and parameter values.

2. Binning Definition File: Supplies the definitions of the binning characteristics and the corresponding Boolean expressions. This file also contains sorting input information whenever sorting is specified.

\section{Code Application}

EVNTRE was developed to process complex event trees that systematically follow the progression of severe accidents in nuclear power plants. This type of assessment is a particularly difficult type of analysis to accomplish. The capacity of EVNTRE to handle large problems allows time dependence to be treated by identifying several times regimes and constructing sets of questions (e.g., systems operation, containment loads, and status appropriate for each time regime).

\section{Historical Development}

The generalized event tree processor, EVNTRE, was developed at Sandia National Laboratories for use in probabilistic risk analyses of severe accident progressions for nuclear power plants. 
Code Title: LHS (Latin Hypercube Sampling)

Code Description

LHS is a code designed to produce either random (Monte Cario) or latin Hypercube samples for a set of one or more random variables with distributions as prescribed by the user. A variety of sampling distributions are built into the code, e.g., normal, lognormal, beta, uniform, triangular, etc., and provisions for inclusion of user written subroutines for sampling from specialized or empirical distributions has been made.

The LHS code uses no input other than the input file constructed by the user. If the user distribution subroutines have been specially modified, the input file will include whatever specific distribution information is necessary for the calculations.

\section{Code Applications}

The Monte Carlo or Latin Hypercube Samples generated by LHS can be utilized for any procedure which requires random input with a specified distributional form. Specifically, the output is useful for propagating parameter uncertainty distributions through either computer codes or other functions of random variables. The output format is designed to be interfaced with the TEMAC computer code for assessing the uncertainty distribution of the top event in a fault tree logic expression, but it is not restricted to this use.

\section{Historical Development}

The LHS code was developed at Sandia National Laboratories in the early/mid 1980 's by R. Iman and M. Shortencarier. No subsequent substantive development is known. The code is designed to work in a VAX computing environment, however, a Macintosh based version with a modified interface is currently in use at SRS (as well as the VAX version). 
Code Title: MACCS

\section{Code Description}

The purpose of the third level of analysis (Level 3) in a Probabilistic Risk Assessment (PRA) is to estimate the consequences due to hypothetical reactor accidents. Both onsite and offsite consequences are calculated in a typical DOE facility PRA. Source terms ascribed to the reactor accidents described above are calculated based on mechanistic computer models and engineering judgment and are binned to reduce tens of thousands of source terms to a more manageable number. Once formulated, the source terms are processed using consequence analysis codes. An individual calculation of this nature models the dispersal of radioactive material away from the reactor building source, accounts for the disposition of radionuclides released, and estimates the health effects and economics effects than could occur. The principal code supported by the U.S. Nuclear Regulatory Commission (USNRC) for best-estimate application for consequence determination is Sandia National Laboratories (SNL) MELCOR Accident Consequence Code System (MACCS). Version 1.5 has been made operational at Savannah River for use in the Level 3 PRA for reactor operation and is the primary methodology applied to the Rev. 0 Level 3 PRA.

MACCS models plume rise (with Briggs models) from the release point, dispersion downwind with a Gaussian model, deposition of radionuclides due (1) both wet (washout) and dry deposition mechanisms, biospheric transport, radiation doses from cloudshine, groundshine, inhalation and ingestion, the mitigation of these doses by emergency response actions, health effects from incurred doses, and the economic costs attributable to emergency response, decontamination, interdiction, and crop disposal.

\section{Database Description}

The MACCS 1.5 code is operational via command file procedures on a VAX operating system (VMS 5.3). Directories for source code, executable, input data, and output data files are found in master directories RSR and RSR2.

Required input to MACCS includes: reactor inventory, release fraction timing (duration and time from shutdown) for each of the release classes, one year of hourly meteorological data, population distributions for onsite and offsite around the Savannah River area, land usage data, and economic data. For cases assuming implementation of sheltering and/or evacuation plans, the analysis must input additionally the time for the start of the mitigative action, the 
segment of the population affected, effective radial evacuation speed, and sheltering protection factors.

The MACCS inventory for the $\mathrm{K}$ Reactor uniform charge is arranged into ten release groups: (1) Noble gases ( $\mathrm{Kr}, \mathrm{Xe})$; (2) Halogens (I);

(3) Alkali metals (Cs, Rb); (4) Group V and VI elements ( $\mathrm{Te}, \mathrm{Sb}$ );

(5) alkaline-earths ( $\mathrm{Sr})$; (6) Ruthenium (Co, Mo, Tc, Ru, Rh);

(7) Lanthanum (Y, Zr, Nb, La, Pr, Nd, Am, Cm); (8) Cerium (Ce, Np, Pu); (9) a second alkaline-earth $(\mathrm{Ba})$; and (10) tritium. The release from a given group is specified by start time and duration for each released plume segment. The ten-group architecture allows different characterization of transport characteristics for radionuclides in the plume (e.g. noble gases are not subject to wet or dry deposition while tritium may be given characteristics appropriate to HTO or HT).

MACCS and its predecessors (CRAC and CRAC2) are best-estimate codes suitable for PRA application. However, several modeling features should be noted with respect to programs written for conservative compliance requirement meeting DOE orders or NRC guidelines. These are: (1) MACCS is limited to six stability categories and does not have the least dispersive category G; (2) MACCS assumes a flat-earth topography; (3) MACCS includes washout of nuclides from the plume if rainfall is occurring; and (4) MACCS does not include jet rise effects.

The tritium dose conversion factors for various organs in MACCS are based on ICRP 30 recommendations and are identical to the assessment provided by Fetter for the FUSCRAC3 code. Although MACCS 1.4 does not have a wholebody dose category, the PRA-basis code MACCS 1.5 does computer EDE wholebody doses.

Code Application

MACCS applications include emergency response sensitivity assessments, siting studies of new reactor facilities, economic $\cdots$ m/henefit analysis, and severe accident assessments associait with Level \& PRA. This section shall describe the Level 3 application only.

Population or collective doses are determined first. Health effects and economic impacts are subsequently calculated. Health effects calculated in a PRA analysis include short-term (radiation exposure-induced fatalities and injuries) and long-term (latent cancer fatalities and injuries) categories. Models interpreting the doses to individual target organs for various health effects are discussed in "Health Effects Models for Nuclear Power Plant Accident 
Consequence Analysis," NUREG/CR-4214 Rev 1, issued by Sandia National Laboratories in 1989. These models are based in turn on the 1980 BEIR-III study (The Effects on Populations of Exposure to Low Levels of Ionizing Radiation, National Research Council Committee on the Biological Effects of Ionizing Radiations, National Academy of Sciences, National Academy Press, Washington D.C.). The cancer estimates provided in this section are summed over leukemia, bone, breast, lung, gastrointestinal, thyroid, and other types (reflecting combined risks of multiple myeloma, lymphoma, and cancers of the bladder, kidney, brain, ovary, uterus, and cervix). A quadratic model is used to address cancer risk for organ doses below a threshold of $1.5 \mathrm{~Sv}$ (150 rem). Beyond that level, a linear fit is employed.

MACCS bins a year of weather data into twenty-nine categories depending on Paquill-Gifford conditions, possible rainfall occurrence, and wind slowdown conditions. For the SID analysis, four samples or possible "start" times are chosen by a Latin Hypercube Sampling (LHS) algorithm in MACCS for each of the twenty-nine bins. Thus, over 100 possible combinations of weather trials affecting the population in sixteen compass sectors are examined for each measure of consequence, yielding over 1600 results. A probability of a result is dependent upon the number of hours in the MACCS weather bin normalized by the total number of hours in a year. The results are indicated in a complementary cumulative distribution function (CCDF) format, whereby the conditional probability of exceeding a level $X_{i}$ of consequence is plotted as a function of the consequences, $X_{i}$. A typical curve would then show the conditional exceedance probability versus number of consequences, and would range from a high conditional probability - low consequence portion to a low probability - high consequence portion. The measure of consequence typically examined in the CCDF plots are: (1) conditional prompt fatalities, (2) prompt fatality risk, (3) latent cancer cases, (4) latent cancer risk, and $(5,6)$ doses to onsite personnel and offsite populations, respectively. Publication of safety goal policies from the USNRC and the DOE has focused attention primarily on the second and fourth measures. To become useful for comparison against the safety goals, the MACCS conditional sequence quantity $\mathrm{C}_{\mathrm{ij}}$ must be weighted by frequency for the particular release category, $\mathrm{RC}_{\mathrm{i}}$, then summed over all release categories to produce the risk of that consequence, $R_{j}$, or, 


$$
R_{j}=\sum_{i=1}^{K} R C_{i} C_{i j}
$$

where $\mathrm{K}$ is total number of release categories considered.

MACCS-applicable meteorological data files for $\mathrm{K}$-area for the years 1982 to 1986 inclusive were developed by SRL in 1987 and consists of hourly data derived from $\mathrm{K}$-area meteorological tower and Augusta (Bush Field) Airport readings. For the PRA study, 1986 weather is used; it was shown that execution of MACCS with this year gives mid-range or high results relative to the other four years of hourly data. Mixing layer height data is included seasonally in the same datasets. For the Gaussian plume model in MACCS, these heights limit buoyant plume rise and vertical growth. Offsite and onsite cases use seasonal afternoon mixing layer heights as published by SRL. Onsite cases calculated for the EIS and the SID, with a day-averaged population database, used an average of the peak afternoon height and early morning heights.

Land usage factors are processed by the MACCS code and used in the calculation of chronic, long-term health effects. These effects are primarily due to food pathway uptake of radionuclides. The data for the PRA are taken from the 1987 Statistical Abstract of the United States, 107th edition (1987) published by the U.S. Department of Commerce. The data to MACCS reflect a thirteen state, thirteen region coverage augmented by factors applicable to the Savannah River Site and the Atlantic Ocean for offsite cases. Onsite MACCS cases do not utilize any of these data, since only the early-phase, non-chronic portion of the accident is considered. Economic data for the offsite cases are also drawn from the same source for computation of economic effects of the source term.

The above data have been assigned to three MACCS grids for calculation of consequences: (1) Onsite, consisting of one-mile radial rings from 1 to 10 miles from $\mathrm{K}$ Reactor, and two-mile intervals from ten miles to twenty miles; (2) Offsite/near-field, consisting of one-mile rings from 0 to 22 miles from $\mathrm{K}$ Reactor; and (3) Offsite/far-field, consisting of 0 to 1000 miles offsite from $\mathrm{K}$ Reactor. The onsite grid is used to compute seven complementary cumulative distribution functions (CCDFs): (1) prompt fatalities from 0 to 1 mile of $\mathrm{K}$ Reactor; (2) all SRS prompt fatalities; (3) latent cancer cases from 0 to 10 miles of K Reactor; (4) all induced latent cases; (5) the total red bone marrow population dose; (6) the prompt fatality death risk ( 0 to 1 mile); and (7) the latent death risk (0 to 10 mile). The near-field offsite grid allows computation of five quantities: (1) prompt fatalities within one mile of the DOE reservation 
boundary; (2) offsite prompt fatalities within 20 miles of K Reactor; (3) the total latent cases induced within 10 miles of the DOE reservation boundary; (4) the prompt fatality death risk ( 0 to 1 mile); and (5) the total latent death risk (0) to 10 miles of the DOE reservation boundary). The far-field of fsite grid is used to compute three CCDFs; (1) the total latent cases induced (0 to 1000 miles); (2) the population dose to red bone marrow ( 0 to 1000 miles); and (3) the total economic costs associated with the source term in 1987 dollars.

\section{Historical Development}

The MACCS code development at Sandia National Laboratories began with the WASH-1400 studies reported in the mid-1970s. This methodology replaces the CRAC and CRAC2 (1983) effort supported by the USNRC since the Rasmussen report. MACCS Version 1.4 was released in 1987 by SNL. Tritium was incorporated into the dose conversion file (DCF) for Version 1.4 by SRL in mid1988. This modification permits calculation of effects due to inhalation and water ingestion from the initial plume passage and due to resuspended tritium. Ingestion of tritium by offsite populations through the food pathway is calculated independently of MACCS.

MACCS 1.5 was released to the NESC and RSIC distribution centers in April 1990. It has received independent quality assurance and verification review from C. A. Dobbe, et al., at INEL (NUREG/CR-5376). MACCS 1.5 was received in November 1990 by RSRS/SRL. It was tested and found to be acceptable for PRA analyses. 
Code Title: MARY

Code Description

MARY is an IBM PC developed computer code used for simulating transient events that may occur in the SRS reactors. It includes models for the Mark 22 assemblies (USH, fuel, target, and coolant regions), moderator upflow and downflow regions (with mixing permitted between them), selected scram signals, single Process Water System loop, and solution of the neutron point kinetics equations. Input provisions include time dependent reactivity, power, flow, inlet temperature, and power distribution.

Database Description

Light-water properties are taken from the 1984 National Institute of Standards and Technology/National Research Council Steam Tables while heavy-water properties are taken from the 1981 AECL Tables.

Code Applications

MARY is used for safety analysis of certain non-LOCA events that will be reported in Chapter 15 of the Safety Analysis Report. Other uses include assessing impact of plant modifications, reduction of plant test data, and general engineering analysis.

\section{Historical Development}

MARY was developed in 1989 by Westinghouse. Version 3.00 was configured on January 23, 1990 and has been modified for use on the VAX (Version 3.01 ).Version 3.02 is currently being under development. 
Code Title: MELCOR/SR

Code Description

The MELCOR/SR computer code models the phenomena pertinent to the quantification of in-plant consequences from selected hypothetical core melt accidents in SRL reactors. Accident scenarios are treated from the start of fuel/target damage through core melt progression, vessel breach, confinement building response (not structural), and radionuclide release to the environment. The modular code is designed to facilitate parametric/uncertainty analyses of severe accident phenomena. The code is considered to be "fast running." To achieve this, many phenomenological representations include empirical treatments in concert with mechanistic modeling.

Database Description

The database is under development at the present time and will include a standard deck for the SRL confinement system.

\section{Code Applications}

The code has been compared with the TRAC code for a reactor transient involving steaming and fuel damage, and the results of the two codes were similar. The code is currently being used to evaluate the response of the SRL confinement system.

\section{Historical Development}

MELCOR was developed at the NRC's request by SNL for commercial light water reactors following the Three Mile Island dccident. MELCOR/SR is a version of the code being adapted by SAIC to model the unique core, materials, and confinement system characteristics of SRL reactors. 


\section{Code Title: PIPEFLOW}

\section{Code Description}

The PIPEFLOW code is a nationally known hydraulic code used to analyze steady state pressure and flow in pipe distributions. The basis of the code is a direct solution of the pipe system of hydraulic equations using a linearization scheme and sparse matrix methods to handle the co-linear terms in the energy equations.

\section{Database Description}

Empirical data contained within the code include loss coefficients for different types of pipe fittings, as well as other correlations adequate for the entire spectrum of Reynolds numbers, from laminar through turbulent flow regions.

\section{Code Applications}

PIPEFLOW is used for a variety of problems at SRS, including the development of a cooling water and emergency cooling system model for use in the SRS Reactor Training Simulator, as well as to calculate cooling water system leak flows for the Probabilistic Risk Assessment (Level 1 PRA) for the SRS reactors.

\section{Historical Development}

The May 1983 version of PIPEFLOW, purchased by the Engineering Department, includes several modifications requested by SRL to improve hydraulic modeling of the Reactor Training Simulator. The most significant modifications include:

1. Calculation of "tee" and "wye" fitting hydraulic losses (which are a function of branch flow splits and area ratios) and

2. Calculation of other fitting (e.g., valves, elbows, etc.) hydraulic losses by the more accurate "two-K" method, instead of the standard "number of velocity heads" or "equivalent pipe lengths" methods. The "two-K" method is valid for the whole spectrum of Reynolds numbers, whereas the other standard methods are valid only for Reynolds numbers corresponding to fully developed turbulent flow. The August 1987 version of PIPEFLOW includes modifications by SRL in the summary printout to account for key data related to the fourth emergency cooling system addition system. 
Code Title: PREP

Code Description

The PREP code is a computer program developed to facilitate use of the SETS computer program for the Savannah River Reactor PRA.

Database Description

The PREP code is documented in DPST-88-566, "PREP, A Computer Program To Facilitate Use Of The SETS Computer Program For The Savannah River Reactors PRA," May 1988.

The PREP code uses a number of text files. In order to keep the files organized. as well as to simplify user input, the following filename extensions are used:

.FT fault tree file

.FLG flag file

.DB probability data file

.ET event tree file

.SET SETS input file

.OUT output file from SETS

Code Applications

The PREP (Fault Tree Pre-processor) code is used to provide a simple user input scheme for the SETS fault tree evaluation code. This includes a simple fault tree input format, linking of data and flag settings, error detection to assure that the SETS job will not abort due to incorrect input, and linking of many fault trees into many event tree sequences.

The software is designed to run on a VAX computer operating VMS. The created SETS input file can then be transmitted to any computer running SETS, such as the CRAY.

Historical Development

As part of Contract AX 654759 to provide technical support to the PRA for the Savannah River Reactors, Science Applications International Corporation (SAIC) developed the PREP computer program to facilitate the use of the SETS computer program in the solution of fault trees and event trees for the PRA. 


\section{Code Title: SCDAP/RELAP5}

\section{Code Description}

SCDAP/RELAP5 is a reactor system transient analysis code that can be used for simulation of a wide variety of transients of interest in both light and heavy water reactor safety. The primary system, secondary system, feedwater train, system controls, and core neutronics can be simulated. The code models have been designed to permit simulation of postulated accidents ranging from large break loss-of-conlant accidents to accidents involving the plant controls and fuel system. Severe accident transient conditions can be modeled from the initial thermal hydraulic phise to the fuel damage/ relocation phase and to thcse phases of the trancient in which debris beds are formed and corium is transported throughout the reactor system. If desired, the transport of volatile fission products and aerosols can be modeled.

SCDAF/RELAP5 was developed by integrating three separate codes, RELAP5/MOD2, SCDAP, and TRAP-MELT. These codes were combined to model the coupled interactions that can occur between the core, the process system, and ih" fission products during a severe accident. The RELAP5 subcode is based on a nonhomogeneous and nonequilibrium model for the two-phese system and was develof $: d$ with the objective of producing a code that includes important first-cider effects necessary for accurate predictions of system transients but is sufficiently simple and cost-effective such that parametric or sensitivity studies are possible. The SCDAP code models the core behavior during a severe accident while the TRAP-MELT code inndels the behavior of fission products and aerosols within the process system.

The RELAP5 subcode solves six basic nonhomogeneous, nonequilibrium field equations for six dependent variables - pressure $(P)$, specific internal energies $\left(U_{g}\right.$ and $\left.U_{f}\right)$, void fractions (a), and velocities $\left(v_{g}\right.$ and $\left.v_{f}\right)$, by a fast, partially implicit numerical scheme io permit economical calculation of system transients. The equation set is extended to include the presence of a noncondensible component and a liquid solute component through the addition of a mass conservation equation for each of the additional components. The field equations for the two-fluid model consist of two phasic continuity equations, two phasic momentum equations, and two phasic energy equations. The equations are recorded in differential streamtube form in terms of time and volume average dependent variables, with time and one space dimension as independent variables.

Structural components such as reactor vessel and piping can be modeled w. heat structures which communicate with the primary or secondary coolant. 
The one-dimensional heat conduction equation is solved for each heat structure, with a variety of boundary conditions available to the user. Reactor power can be input by the user or calculated with a point kinetics model that includes reactivity feedback from fuel and water temperature, control rods, and boron (or other soluble poisons).

Core components, such as fuel or target tubes, sparjets, or electrical heater rods, are modeled by specific components within the SCDAP subcode. Treatment of the core includes fuel and target tube heatup with one- or two-dimensional heat conduction, aluminum melting and oxidation, fission product release, flow and freezing of molten fuel and target, and debris formation and behavior. Debris bed thermal response is modeled by the COUPLE finite element subcode. This subcode models two-dimensional heat conduction across the debris beds, while those debris beds may exist either at the bottom of the reactor vessel or within the process water system.

Fission product transport is modeled by the TRAP-MELT subcode, which analyzes the transport and deposition of both volatile fission products and aerosols. This treatment includes aerosol agglomeration (including Brownian motion, gravitational settling, and turbulent eddy effects), aerosol deposition (including gravitational settling, thermophoresis, and diffusion from laminar or turbulent flow), fission product evaporation and condensation, and chemsorption of vapors onto metals.

\section{Database Description}

Material properties are taken from the MATPRO library of properties. This library was generated by the Idaho Natioulal Engineering Laboratory to describe reactor materials under a wide range of physical conditions, including the severe conditions expected during reactor operating and accident situations.

Steam and water properties are based on ASME Steam Tables for light water properties, and upon data from the University of British Columbia for heavy water. The tables of heavy water properties were generated by using a SASA code as modified by the Helmholtz free energy equation and the saturation equation taken from the Canadian data of Hill et al.

Code Applications

SCDAP/RELAP5 provides analytical support for NRC rule making, licensing audit calculations, evaluation of accident mitigation strategies, and experiment planning and analysis. Specific applications have included analytical support for the Loss of Fluid Test (LOFT), Power Burst Facility (PBF), ACRR, MIST, ROSA- 
IV, and NRU experimental programs. SCDAP/RELAP5 was successfully used within the Three Mile Island Accident Evaluation Program, as well as to support revisions to the Advanced Test Reactor (ATR) Safety Analysis Report.

\section{Historical Development}

The series of RELAP5 codes began at the Idaho national Engineering Laboratory with RELAPSE (REactor Leak And Power Safety Excursion), which was released in 1966. In subsequent versions of this code (RELAP2, RELAP3, RELAP4), the original name was shortened to Reactor Excursion and Leak Analysis Program (RELAP). All of these codes were based on a homogeneous equilibrium model of the two-phase flow process. The need for a two-fluid nonequilibrium nonhomogeneous hydrodynamic model for transient simulation of two-phase behavior led to the development of RELAP5.

A parallel effort was begun in 1977 to integrate the Severe Core Damage Analysis Program (SCDAP) in order to develop a state-of-the-art severe accident analysis tool. TRAP-MELT and COUPLE were integrated as the need for additional severe accident analysis capability grew. 
Code Title: SETS

Code Description

The Set Equation Transformation System (SETS) computer code is used to solve fault trees and to perform the accident sequence analysis task for Probabilistic Risk Assessments (PRAs). Other tasks in a PRA provide the input tot he fault tree and the accident sequence analysis tasks. The SETS computer program is used to process these inputs to identify the dominant failure modes and to compute an approximate frequency of occurrence for a fault tree or accident sequence.

The SETS computer program is being used to perform the system/ component level portion and accident sequence analysis portion of the Savannah River Reactors PRA. The SETS version used at SRS is CRAYSETS, which is a proprietary code. CRAYSETS is especially designed to use the SETS code (with enhancements) on the CRAY computer.

\section{Database Description}

The SETS computer program accepts input in the form of fault trees, Boolean equations, and point values. A SETS user program directs the processing of the input and the order in which it occurs. The SETS program uses three different files: the equation file, the block file, and the value block file. The equation file is a work file used to process equations. The value block file is a data storage file used to store value assignments. The analyst uses SETS procedure calls to read fault trees and equations onto the block file and to load them from the block file into the equation file. Depending on the type of solution required, additional SETS procedure calls are use's to solve the equations in the equation file. The solution equations can be either printed or stored back on the block file.

\section{Code Applications}

The failure of a plant safety system is mathematically modeled by a fault tree. The SETS code is used to determine the fundamental ways in which the system can fail as a result of combinations of events such as hardware failures, human errors, procedural inadequacies, and test and maintenance outages. For a given accident sequence, the SETS code is used to combine these fault tree solutions in a manner consistent with the definition of the accident sequence to identify the fundamental ways in which the accident sequence can occur and to compute an approximate frequency of occurrence for the accident sequence. 


\section{Historical Development}

The SETS computer program was developed by R. B. Worrell at Sandia National Laboratories, Albuquerque, New Mexico. A CDC 7600 version of SETS dated April 8, 1985, is available from the National Energy Software Center (NESC) in Argonne, Illinois. The SETS code has been used for fault tree analysis for many years. More recently, the SETS code was enhanced in order to be used for accident sequence analysis. SETS was sued to perform the accident sequence analysis for three nuclear power plants as part of the Interim Reliability Evaluation Program (IREP) analyses. As a result of the experience gained in the IREP analyses, new capabilities were included in SETS and existing capabilities were enhanced. This resulted in an accident sequence version of sets that facilitates the implementation of the steps in an accident sequence analysis.

The CRAY version of SETS (CRAYSETS) used at SRS (dated January 9, 1989) is proprietary, copyrighted software developed by R. B. Worrell for Logic Analysts. 
Code Title: TEMAC

Code Description

TEMAC is a code designed to calculate the top event frequency associated with a complex logic expression from a fault tree calculation. This expression can be a function of many events, and the code also calculates the "partial derivative, risk increase, and risk decrease" for each event in the logic expression as it relates to the top event. It also has the ability to propagate random samples of the events through the logic expression in order to arrive at a probability distribution for the top event. In this case, an uncertainty importance" calculation can also be performed to rank the events in the logic expression by their contributions to the variance of the top event distribution. A recent addition to the code's capability is the ability to assess all of the above for subsets of the cutsets in the logic expression. This is useful for "binning" the cutsets for input to a Level 2 PRA analysis.

\section{Database Description}

The TEMAC code uses five input files: four of which are generated directly by the user. If an uncertainty propagation is requested in the first input file, then input file number five contains a random or Latin Hypercube sample in the format generated by the LHS code.

\section{Code Applications}

The TEMAC code can be used to calculate the result and distribution of any simple, or not so simple function of random variables (restricted to multiplications and additions of the variables). It does, however, assume that the function is a logic expression from a fault tree and performs error checking on the expression and its input values with this assumption in mind.

Therefore, arbitrary functions may encounter difficulty.

\section{Historical Development}

The TEMAC code was developed at Sandia National Laboratories in the mid 1980 's by R. Iman and M. Shortencarier. Recently, the capability to bin cutsets has been added to the code. The code is designed to work in a VAX computing environment. Two versions of the TEMAC code exist at SRS, one as supplied by Sandia, and one as modified per TEMAC user manual instructions to increase its capabilities. 

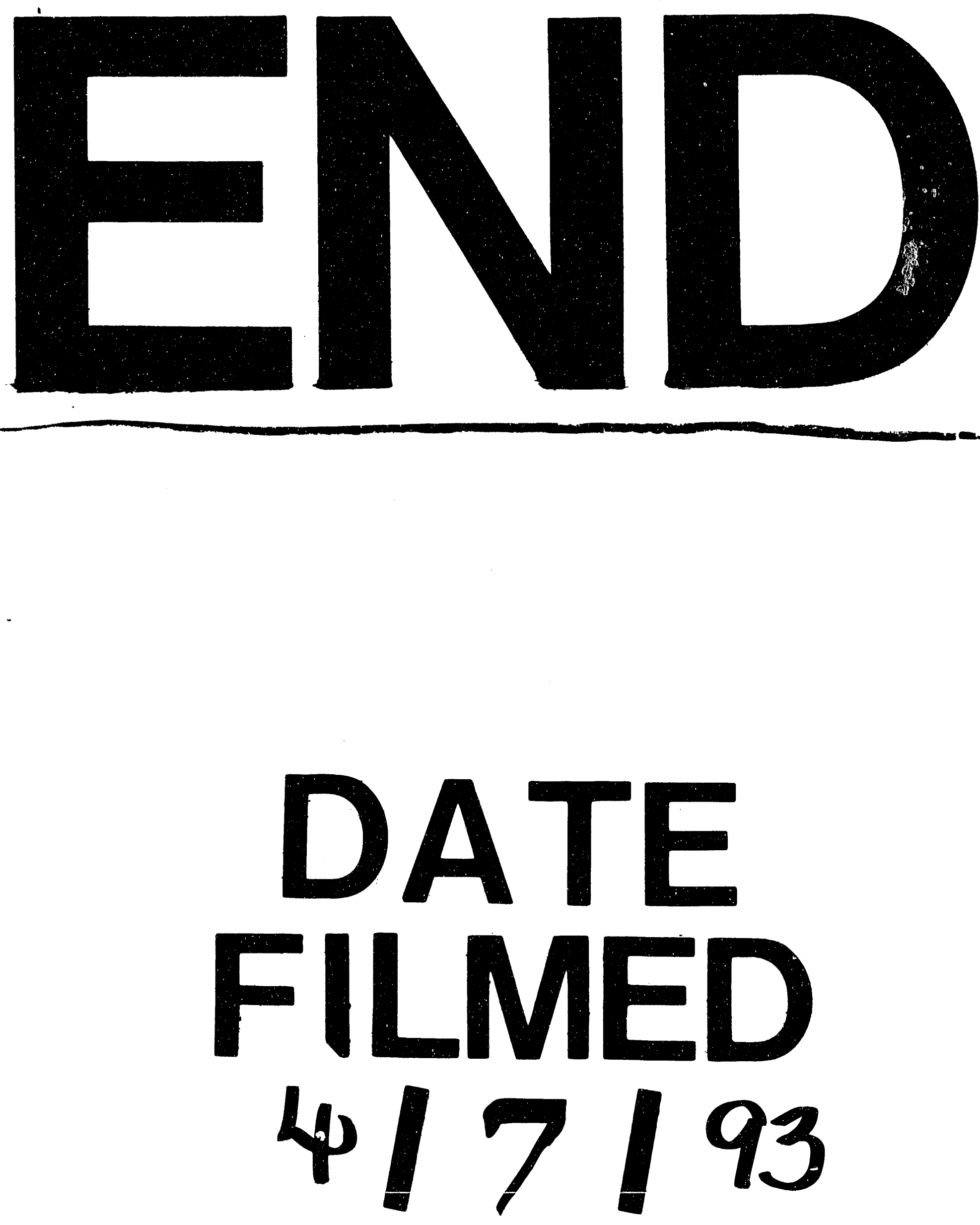
